\title{
Feasibility study of orientation for the blind in Vilnius
}

\author{
Artūras Bautrènas $^{\mathrm{a}}$, Aliona Buiko ${ }^{\mathrm{b}}$, Diana Raudoniene $\dot{\mathrm{c}}^{\mathrm{c}}$ \\ ${ }^{a}$ Vilnius University, M. K. Čiurlionio str. 21/27, 03101 Vilnius, Lithuania \\ ${ }^{b}$ SE ,. GIS-Centras", Seliu str. 66, 08109 Vilnius, Lithuania \\ ${ }^{c}$ Vilnius Academy of Arts, Maironio str. 6, 01124 Vilnius, Lithuania
}

\begin{abstract}
The main provision of the concept of social disability indicates that the situation, which a person with physical or mental disability experiences as a situation with limiting abilities, is created not as much by the compromised physical functions, but by the obstacles in their living - physical and social - environment. These obstacles, not the specific consequences of compromised bodily functions (inability to control extremities, inability to see, etc.) determine whether a person with limited abilities can independently participate in the activities, which normally involve other members of the society. The aim of the study is to map places in Vilnius most frequently visited by the blind, to evaluate the obstacles present in those places and their level of danger, and to create methodology, which could allow facilitating orientation for the blind in such places. During the research, having applied the new technology for tracking the moving direction of the blind and having summarised the data of the survey of the blind, the points of the territory most frequently visited by the blind were determined, a large-scale (1:100) topographic plan of the territory was compiled, and the optimal routes of movement of the blind were determined. Pursuant to the gathered topographic information and analysis of the skills of orientation of the blind, the methodology allowing to assess the mapped territory for orientation from the point of view of its quality and to indicate the zones hazardous for the blind was created. The methodology for provision of information was created and new methods of creation of tactile maps were tested, which will facilitate orientation of the blind in the living environment.
\end{abstract}

Keywords: cartography; tactile map; blind person; travel "tunnel".

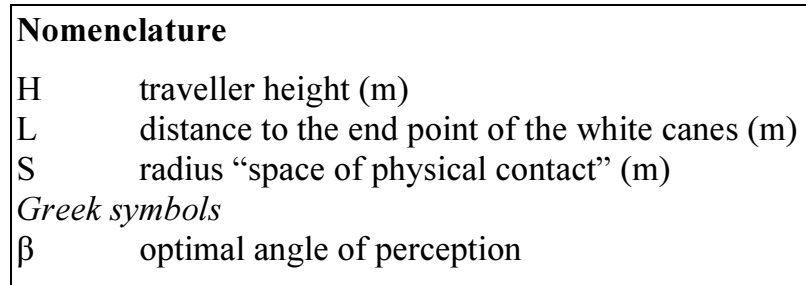

\section{Introduction}

City streets are not just roads connecting one part of the city with another. It is a complete system of public communications with a particular infrastructure. It is not just a traffic area or pavement; it is a combination of different elements of the streets: crossroads, road signs, public transport stops, green plantations, illumination and underground communication networks, structures of different designated purposes, and many other objects, the main purpose of which is to satisfy the needs and functioning of public communications. This communication system is used by everyone, even city residents or guests with certain disabilities.

The main provision of the concept of social disability indicates that a situation, which a person with physical or mental disability experiences as a situation with limiting abilities, is created not as much by the compromised physical functions, but by the obstacles in their living - physical and social - environment [1-2]. These obstacles, not the specific consequences of compromised bodily functions (inability to control extremities, inability to see, etc.) determine whether a person with

Corresponding author: Artūras Bautrènas. E-mail address: arturas.bautrenas@gf.vu.lt

http://dx.doi.org/10.3846/enviro.2014.189

(C) 2014 The Authors. Published by VGTU Press. This is an open-access article distributed under the terms of the Creative Commons Attribution License, which permits unrestricted use, distribution, and reproduction in any medium, provided the original author and source are credited. 
limited abilities can independently participate in the activities, which normally involve other members of the society. It is especially relevant to people with limited visual abilities, i.e. visually impaired or blind.

Priority of the society, that considers everyone to be its members, not only those without disabilities, is arranging the living environment in such a way as to allow independent activities of people with disabilities.

\section{Problem Formulation}

Obstacles, due to which people with disorders experience a situation with limiting abilities, are different. They are differentiated according to a disability: stairs are an obstacle for a person with movement disabilities, while people with impaired vision experience obstacles through provision of information in a form, which is perceived visually (e.g., red signal of a stop light does not mean anything to the blind, because they simply do not see it).

A person, whose vision is impaired in such a way, where it cannot be used to comprehend the closest environment, can still move around independently in a familiar or everyday environment, for example, in their apartment or in the yard of their house. This orientation, though in the familiar environment, is possible only by using supporting means, which partially compensate vision. In this case the most commonly used tool is the white cane (Fig. 1) designed for physical contact with the environment, i.e. for detection and identification of obstacles [3].

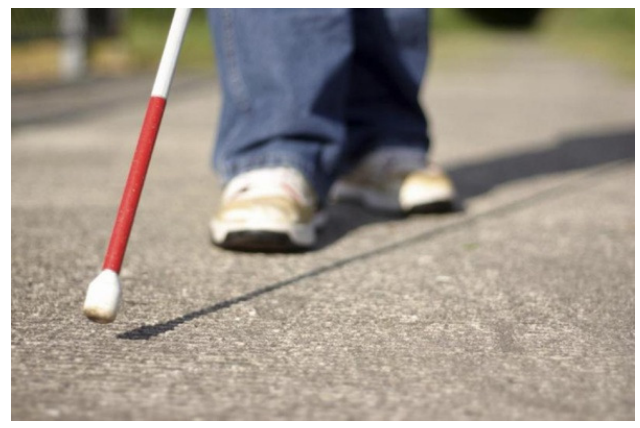

Fig. 1. White cane designed for physical contact with the environment

The blind moving in a familiar environment determines the location with respect to the planned route according to the encountered obstacles and corrects direction of movement correspondingly. Information required to comprehend the route of a journey is received in parts, i.e. it is not the general spatial image of the surrounding environment that is created, but the image of only one particular route. This is why a blind person immediately loses spatial orientation, if they find themselves in the environment they have never been before. This is especially relevant with respect to large spaces, which in big cities are numerous. Orientation of persons with impaired vision is especially difficult in such places, because unknown obstacles and different sources of noise aggravate analysis of the environment [4].

When getting ready to travel independently, a blind person has to plan the whole route of the future journey, therefore, one of the major problems is obtaining sufficient useful information about the environment, where the journey is planned. Any information about the environment would help both to plan the route in advance and during the trip on the route and immediately reacting to possible obstacles.

One of the most optimal sources of such information is a properly compiled tactile map of the required territory (Fig. 2), which would allow the blind to plan their future journey and select the optimal route [5].
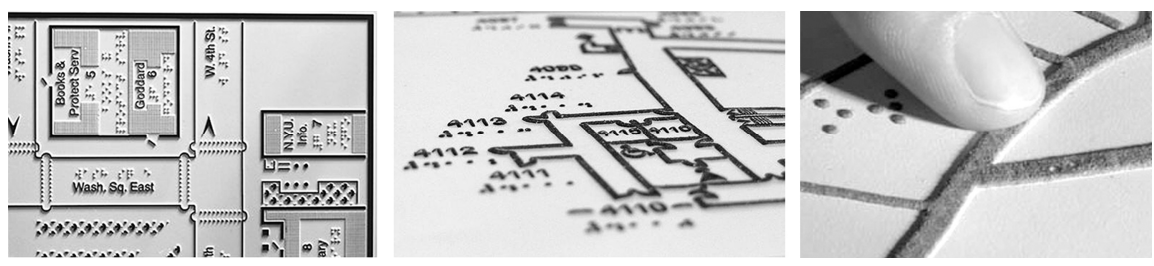

Fig. 2. Fragments of a tactile map

The aim of the carried out research is to determine the points of the most frequently visited territories (in the city of Vilnius) and direction of possible routes of a journey, and to unambiguously evaluate, which objects of the environment become obstacles for the blind, and which help to orientate. In the presence of this data, it would be possible to optimise the created tactile maps in such a way that information provided in the maps could satisfy the needs of the blind to the maximum and facilitate orientation in a place of a journey. 


\section{Research Methods}

The main difference between the tactile maps and the maps we are used to (printed on a piece of paper) is that all textual and graphic information visualized on a tactile map shall be provided using tactual signs or symbols, and text using Braille (Fig. 2) [6-7].

Graphic information presented on a tactual map takes much more space than regular type of printing. For example, whereas the whole plan of the city of Vilnius can be printed on one or several pieces of paper (depending on the scale), tactile type of printing would require ten times more pieces of paper. All objects on the map must be of a certain size comprehensible to the blind. If the object on a tactile map is too small, it will be unperceivable, and if it is too large incomprehensible [8].

It is obvious that it is not necessary to map the whole plan of the city at once, i.e. the blind need to receive information only about those places, which they visit most frequently or hope to visit. It would seem that all it takes is to make good tactile maps of all the places most frequently visited by the city residents or guests and the problem will be solved, however that is not the case. Those places of the city, which are interesting to those who see, can have absolutely no interest to the blind and are hardly visited.

Trying to find the places in Vilnius most frequently visited by the blind, several blind people and people with impaired vision, who voluntarily (anonymously) consented to participate in the experiment, were observed. In order to register the places they visit, GPS devices were attached to their white canes (Fig. 3), which they would turn on before every trip they took.

This GPS model BT-Q1300 was chosen because of several reasons:

- It is compact and very light (its weight is only $22 \mathrm{~g}$ ), therefore does not interfere with the movement of the blind.

- Its control is maximally automated, i.e. the device only needs to be turned on and all measurements are carried out automatically. This is especially convenient for the blind, who do not have such measurement skills.

- It registers only the main data of a track (sequences of the track points, coordinates and distances), up to 200000 track points can be saved, i.e. all points of an approximately 10 hour trip.

- Point coordinates, in the presence of favourable measuring conditions, are determined to within 2-3 $\mathrm{m}$ accuracy. This accuracy is sufficient to determine the most frequently visited places in Vilnius.
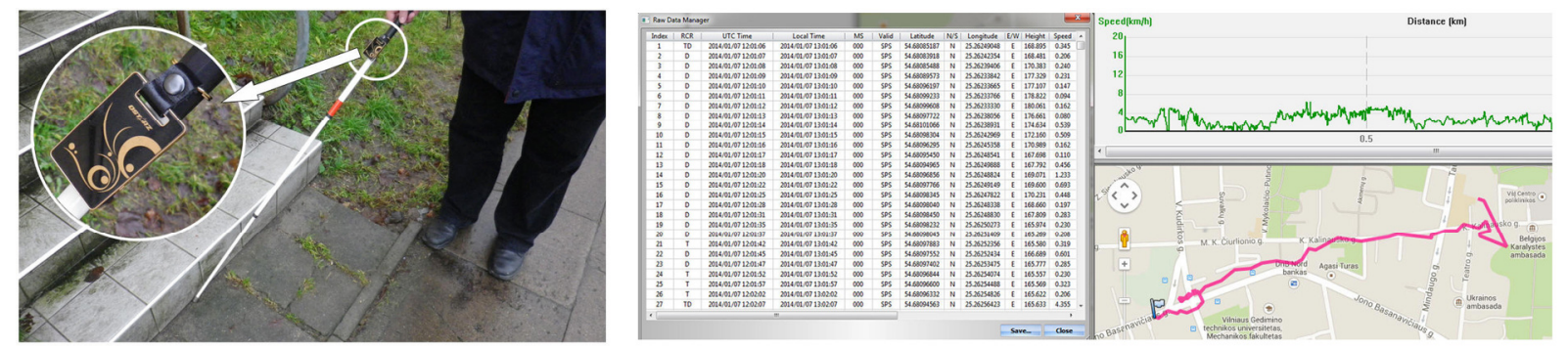

Fig. 3. White cane with a GPS device and specialised software "QTravel"

When measurements are taken in an automatic mode, all the points of a journey are registered every 5 seconds even when the distance between the closest points is larger than 1 metre. This way we receive the track trajectory, the primary analysis of which can be performed using specialised software "QTravel" (Fig. 3), which is provided together with the GPS device.

It is obvious that the more these track trajectories cross or overlap in a certain part of the city, the higher the probability that this will be the most frequently visited place, the points of which can be verified by performing additional measurements.

In order to find the obstacles the blind encounter on their way, it is necessary to know a more precise direction and place of each journey. Unfortunately, during movement through the city, especially on narrow streets or multi-storey buildings, GPS signal [9] is very often compromised; therefore every track point of the journey can be measured at a different accuracy. These measurement errors must be evaluated, and all incorrectly measurement points eliminated from the track, this way verifying (correcting) the travel trajectory registered by the GPS device. In order to accomplish that, it is necessary to understand how the blind move along the selected track.

When travelling to the selected destination, a person with a vision disability carries out two actions at the same time: follows own movement on the planned route and reacts to the real environment, seeking to detect possible obstacles and avoid them. The area, which can be touched by the white cane standing in one point, can be referred to as the "seeing field of the blind" or "space of physical contact" (Fig. 4). 


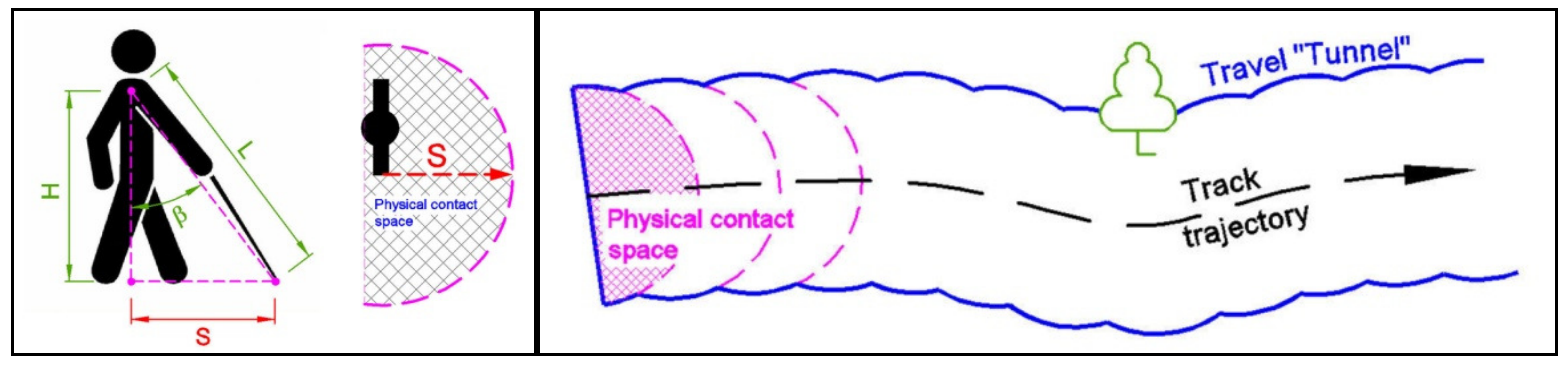

(a)

(b)

Fig. 4. Space of physical contact (a) and a travel "tunnel" (b).

The size of this "space of physical contact" is individual, i.e. it depends on the height $(\mathrm{H})$ of the traveller and distance to the end point of the white canes (L) (Fig. 4a). It was observed that the most optimal angle of perception ( $\beta$ ) is approximately $38^{\circ}$, therefore it is rather simple to calculate the radius (S) of this zone using formula (1) or (2).

$$
\begin{gathered}
S=H \operatorname{tg} \beta \\
S=L \sin \beta
\end{gathered}
$$

When moving in the chosen direction, the track trajectory (Fig. 4b) is formed by a number of single "spaces of physical contact", which can be called a sort of a travel "tunnel". Objects or obstacles outside of its boundaries practically do not exist to the blind, because they cannot reach them with their white canes.

Those points of a track (registered by the GPS device), which do not fall inside this travel "tunnel" are not measured correctly and they can be eliminated (Fig. 5a).

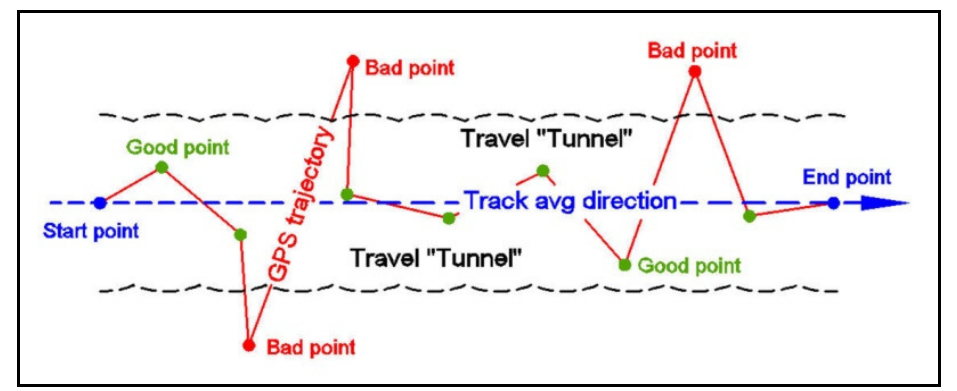

(a)

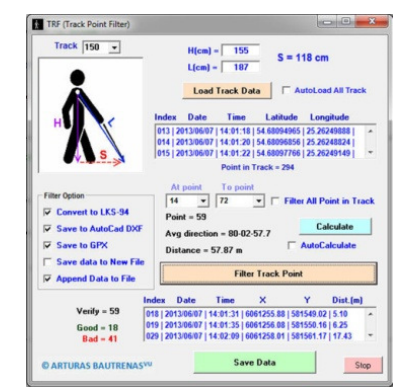

(b)

Fig. 5. Scheme of detection (a) of incorrectly measured track points and Control window (b) of the computer programme TPF

GPS device operating in an automatic mode registers many more track points, i.e. there can be even several thousands of them in one track trajectory. Visual detection of all poorly measured points is practically impossible. The width of the travel "tunnel" is virtual, therefore evaluation of which points apply and which do not, is possible only having carried out mathematical comparison of them. Computer programme [10] for this large volume calculation was created (author Artūras Bautrenas) which is conditionally called the Track Point Filter (TPF) (Fig. 5b).

Principle of operation of TPF computer programme:

- The average radius of the individual "zone of physical contact" of a traveller is calculated.

- Reading of the measured track points of the selected journey is done and converted [11] from WGS coordinate system to LKS-94 coordinate system.

- The average direction of the travel trajectory and virtual limits of the travel "tunnel" are calculated according to the staring and end points of the whole journey or randomly selected interval (Fig. 5a).

- Every point of GPS trajectory is verified. If the verified point does not fall within the calculated travel "tunnel" (Fig. 5a), it is eliminated, if it does - it is saved, but its coordinates are adjusted according to the average direction of the travel trajectory.

- All corrected travel points are saved in a separate database and additionally entered in DFX and GPX formats for further analysis.

\section{Research Results}

During the research, data of 158 travel tracks was gathered, the length of which vary considerably (from 120 to 4800 coordinated track points). There were more than 630000 points registered in total. Having carried out primary visual analysis using the "QTravel" software (Fig. 3), large part of the routes was eliminated, because they were obviously inaccurate or were single-time (not recurring) routes. 
All remaining 26087 points (49 tracks) were converted into the LKS coordinate system and integrated into the common database. The identification of the most frequently visited places was performed using AutoCAD and Google Earth computer programmes.

Having selected the territories, where most coordinated points and crossing travel routes were observed, it was established that most frequently visited places were trade centres, health institutions (clinics, pharmacies) and public leisure zones (parks, squares) (Fig. 6).

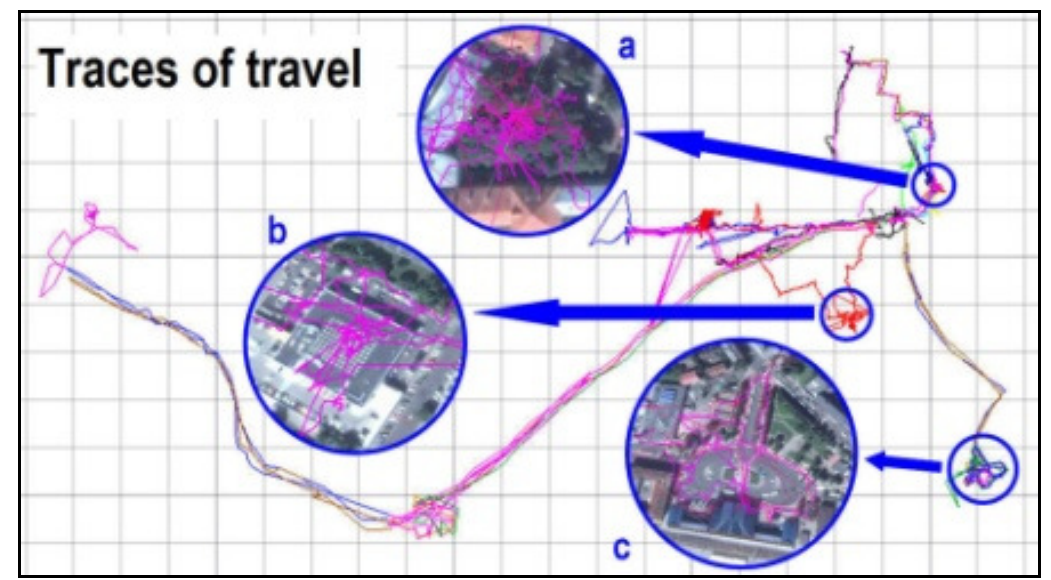

Fig. 6. Fragments of the most frequently visited places: leisure zones (a), trade centres and health institutions (b), “Central Station Region” (c)

The only part of Vilnius, which was visited by practically all the disabled participating in the research, was Vilnius railway and intercity bus stations. This part of Vilnius shall be referred to as the "Central Station Region" (Fig. 6), even though from the administrative point of view such district does not exist in Vilnius.

It is not difficult for the disabled to reach the "Central Station Region", because communication with this part of the city is the best, i.e. all public transport available in Vilnius (trolleybuses, busses) goes there. However, upon arrival, in order to reach the buildings of the railway or bus station, one must cross the area (which essentially is called the "Central Station Region") separating public transport from the intercity transport. This territory is particularly complicated for people with vision disability not only due to the abundance of unknown obstacles, but also due to continuously changing large flows of transport and travelling people. Therefore, all further tests were carried out only on this territory.

In order to evaluate accurately, which areas of the "Central Station Region" was used and which obstacles were encountered, additional topographic measurements were carried out and the large-scale topographic plan of this territory (1:100) was compiled (Fig. 7a), which indicates all the objects and possible obstacles present on the territory. There are a total of 358 marked objects, which the blind can encounter on their way.

All GPS points and travel trajectories measured at the "Central Station Region" were registered on this topographic plan (Fig. 7b).

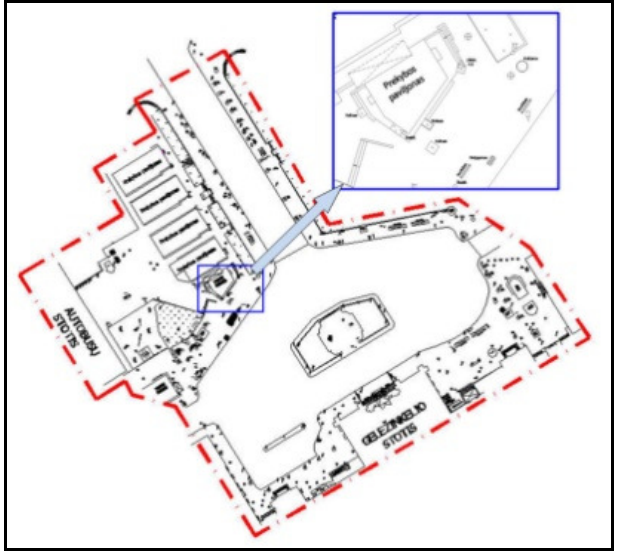

(a)

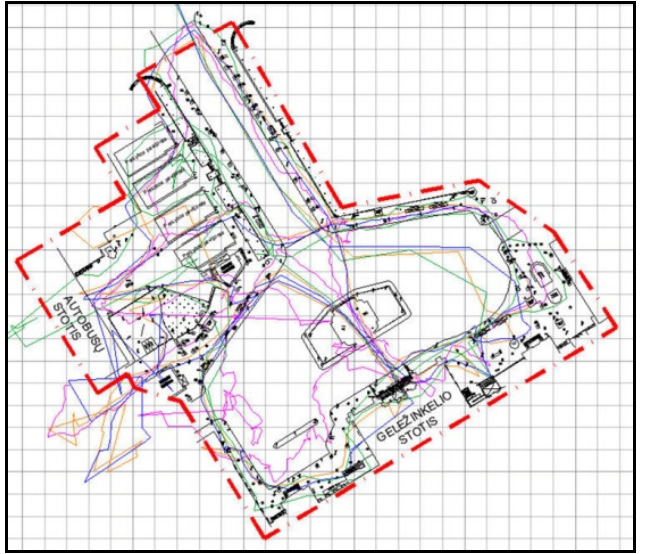

(b)

Fig. 7. Topographic plan (a) of the "Central Station Region" 1:100 and its fragment and Travel trajectories on (b) the topographic plan of the "Central Station Region"

Part of the travel trajectories were eliminated because it was observed (Fig. 7b), that during travel the blind used vehicles (travel trajectory follows the traffic area of the street) or the services of an escort (travel trajectory crosses nearly $30 \mathrm{~m}$ area of the street on the traffic area, which is impossible for the blind to cross independently). Data of the remaining travel trajectories were analysed using a created computer programme TPF (Fig. 5a, 5b). 
Having eliminated all incorrectly measured GPS points and corrected directions of travel trajectories, a joined scheme of travel directions was made (Fig. 8) with the calculated the average width of the travel "tunnel" (Fig. 4b).

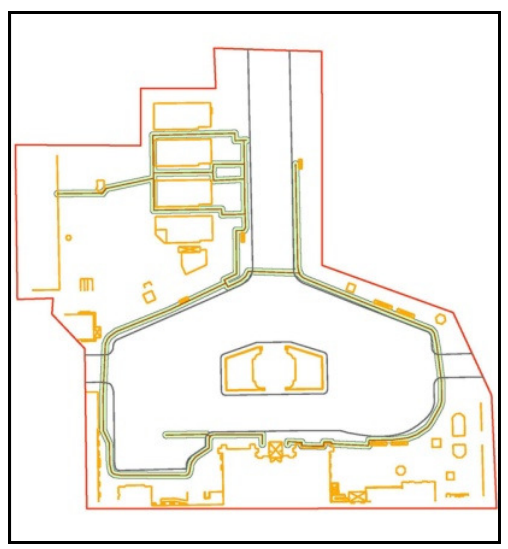

Fig. 8. Scheme of optimised travel trajectories in the "Central Station Region"

The length of the travel trajectories varies between 25 and 330 metres, depending which stop (eight in total) of public transport is used as the starting point of a journey, and direction (bus or railway station). In order to evaluate the level of hazard of the obstacles present in the "Central Station Region" and to select corresponding tactile arbitrary signs, the catalogue of all the objects and obstacles falling within the zones of the travel "tunnel" of the optimised tracks (Table) was created.

All these objects are marked using 25 different arbitrary signs and additional descriptions (e.g. tree types and width) on the topographic plan. This variety of arbitrary signs used by the sighted is not at all necessary for compilation of tactile maps. For example, a lamp pole, road sign or flag post are marked using different signs on the topographic plan, but for the blind these are poles of different width, which can be easily passed.

Having carried out analysis of the objects, they were divided into several groups:

- Stationary and linear objects - large buildings, various structures with foundations, stairs, pavement or street kerbs and retaining walls.

- Stationary small-scale objects - various poles (electricity, lighting, retaining, etc.), pay phones and advertising panels on one leg.

- Flora - single trees of different width and hedges.

- Mobile objects - small-scale objects (trash cans, portable advertising boards or decorative plant boxes), i.e. those objects, which can be easily removed or moved to another place.

- Public transport stops.

Table. Fragment of the catalogue of objects and obstacles

\begin{tabular}{|c|c|c|c|c|c|c|c|}
\hline $\begin{array}{l}\text { Photograph of } \\
\text { an object }\end{array}$ & $\begin{array}{l}\text { Arbitrary signs on } \\
\text { the map }\end{array}$ & $\begin{array}{l}\text { Number of } \\
\text { objects on the } \\
\text { optimised travel } \\
\text { tracks }\end{array}$ & $\begin{array}{l}\text { Number of objects } \\
\text { at the "Central } \\
\text { Station Region" }\end{array}$ & $\begin{array}{l}\text { Photograph of } \\
\text { an object }\end{array}$ & $\begin{array}{l}\text { Arbitrary } \\
\text { signs on the } \\
\text { map }\end{array}$ & $\begin{array}{l}\text { Number of } \\
\text { objects on the } \\
\text { optimised } \\
\text { travel tracks }\end{array}$ & $\begin{array}{l}\text { Number of } \\
\text { objects at the } \\
\text { "Central Station } \\
\text { Region" }\end{array}$ \\
\hline & epa & 37 & 51 & & & 35 & 41 \\
\hline $3 x+y=$ & & 8 & 11 & & & 24 & 40 \\
\hline
\end{tabular}

If certain unitary signs could be applied to the first four groups of objects, supplementing them by textual information using Braille, the public transport stops should be depicted as a complex. They contain objects, which are not present anywhere else (e.g. waiting pavilion, benches, signs marking parking places of vehicles, etc.). In order for the blind to comprehend all objects belonging to the stop as a whole, not as separate objects, the 3D printing technology was used, i.e. a 3D model [12-13] of a required place on a topographic plan was created using the AutoCAD computer programme and printed on a special 3D printer "TierTimeInspire S200" (Fig. 9a). 


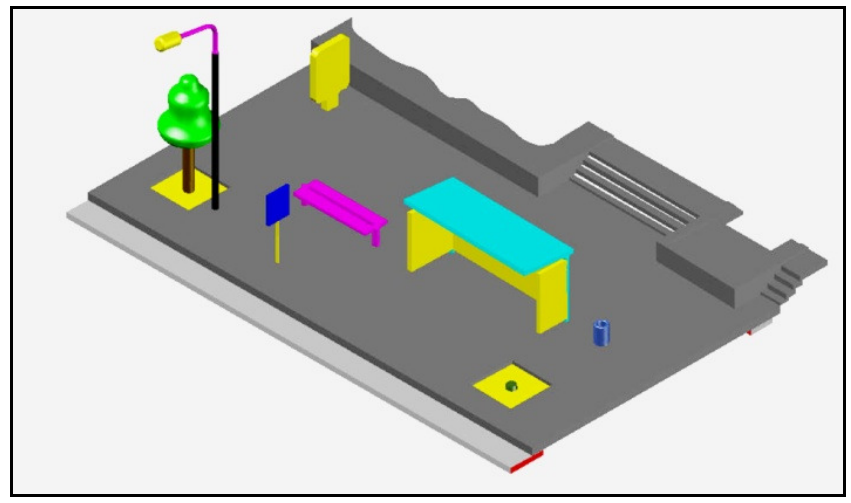

(a)

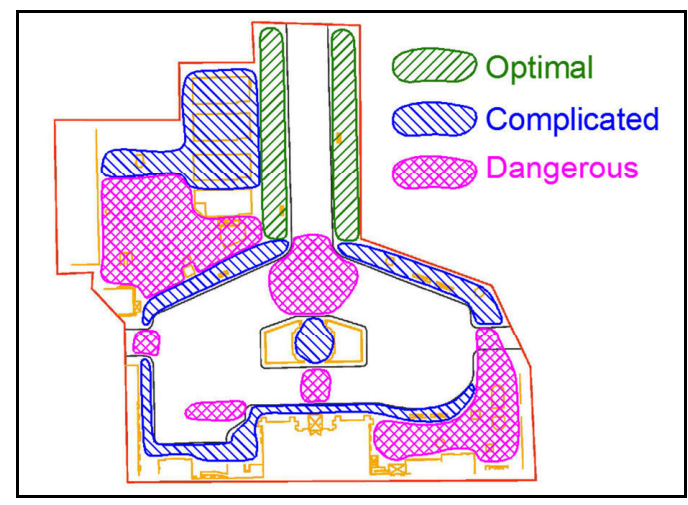

(b)

Fig. 9. 3D model of the public transport stop (a) and scheme of hazards of the zones (b) of the "Central Station Region"

Since, when creating a topographic plan, all the objects of the "Central Station Region" were coordinated, not only the type of objects was analysed, but also the distances between them. Having compared the data of analysis of distances with the data of the survey of the blind, where they described their sensations while travelling on different routes, the scheme of hazards of the parts (zones) of the "Central Station Region" was created (Fig. 9b).

Three types of zones were distinguished according to how the blind orientate themselves in them:

- Optimal - prevalence of linear objects (kerbs, retaining walls, hedges, etc.), and very few other obstacles.

- Complicated - prevalence of various objects with a distance between 2 and 4 meters, and very few linear objects.

- Dangerous - a large number of various objects with a distance of up to 2 metres between them, i.e. several objects fall within the travel "tunnel" at the same time, or larger than $4 \mathrm{~m}$ wide, which have absolutely no landmarks.

\section{Conclusions}

- The chosen GPS device, the main advantage of which is that its measurements are performed automatically and do not create any inconveniences to a blind user, is optimal for these types of researches. Even though in the conditions of a city the GPS signal can be significantly distorted, measurements of such accuracy are sufficient to establish places most frequently visited by the blind.

- In order to receive an exact travel trajectory of the blind, it is necessary to eliminate all points inaccurately registered by the GPS devices. The research demonstrated that the method of selection and elimination of inaccurate points (Fig. 5a) is rather effective, because more than $90 \%$ of inaccurately registered points are detected and eliminated by the computer programme TPF (Fig. 5b) created according to this methodology. Due to the reasons stated above, optimisation of the travel trajectories of the blind is carried out with high precision (does not exceed $1 \mathrm{~m}$ bias) and speed. This method can be used for analysis and mapping of the places most frequently visited in other cities too.

- The research demonstrated that the places most frequently visited by the blind are objects in a close proximity to their place of residence, which neither the city guests nor other blind ever visit. The only place, which is visited by practically all the blind is the "Central Station Region", therefore a good and informative tactile map of this part of the city of Vilnius is necessary, even though for this reason a whole series of small tactile maps will have to be additionally created, which are adjusted for everyday needs of the blind.

- The analysis of the objects and obstacles present on the travel tracks of the blind demonstrated that it is possible to create a common system of tactile sings, which would help the blind to easier understand the information provided on the maps, however additional researches in cooperation with the blind will be required.

- The created orientation method (i.e. where a track "tunnel" of an individual journey with all objects encountered on the way is created) effectively facilitated orientation of the blind during an independent journey. It was observed that space orientation will even more improve, if together with the detailed travel track map a general tactile map of the whole territory ("Central Station Region" in this case) is provided.

- Since the tactile maps of the territories with a high number of mobile objects must be renewed as often as possible, it is best to use combined technologies for creation of these types of maps. The general territory plan is presented with application of prominent tactile map creation technologies and using a common system of arbitrary signs, while the track "tunnel" of an individual journey is formed using spatial elements (trees, pole, benches, etc.) created by 3D printing technologies (Fig. 9a). Upon demand, this 3D travel track model can be quickly adjusted.

- The scheme of hazardous zones (Fig. 9b) of the "Central Station Region" of Vilnius created according to the data obtained during the research demonstrated that at the moment independent travel of the city residents or guests (number of which continues to grow) with impaired vision on this territory is rather complicated, therefore the methodology of collection and presentation of tactile information created during the research will allow not only to promptly provide necessary information to the blind, but will also facilitate their orientation in the environment and increase the opportunity to independently participate in public life. 


\section{References}

[1] Viluckienè, J. 2008. „Iškūnyta“ socialinio modelio negalios samprata [The "disembodied” disability conception of the social model], Filosofija Sociologija [Philosophy. Sociology] 19(4): 45-52.

[2] Swain, J.; French, S.; Barnes, C.; Thomas, C. (Eds.) 2004. Disabling Barriers, Enabling Environments, 2nd Edition. London: Sage Publications.

[3] Tobin, M. 2008. Information: a new paradigm for research into our understanding of blindness?, British Journal of Visual Impairment 26(2): 119127. http://dx.doi.org/10.1177/0264619607088278

[4] Jones, T.; Jain, J. 2006. Examining the experiences of sight-impaired travellers: The next station stop?, British Journal of Visual Impairment 24(3): 141-144. http://dx.doi.org/10.1177/0264619606066198

[5] Marin-Lamellet, C.; Aymond, P. 2008. Combining verbal information and a tactile guidance surface: the most efficient way to guide people with visual impairment in transport stations?, British Journal of Visual Impairment 26(1): 63-81. http://dx.doi.org/10.1177/0264619607083832

[6] Jehoel, S.; McCallum, D.; Rowell, J.; Ungar, S. 2006. An empirical approach on the design of tactile maps and diagrams: The cognitive tactualization approach, British Journal of Visual Impairment 24(2): 67-75. http://dx.doi.org/10.1177/0264619606063402

[7] Gardiner, A.; Perkins, C. 2005. "It's a sort of echo...": Sensory perception of the environment as an aid to tactile map design, British Journal of Visual Impairment 23(2): 84-91. http://dx.doi.org/10.1177/0264619605054780

[8] Bautrènas, A. 2005. Problems of the creation of tactile maps, in Proc. of the 6th international conference on environmental engineering, Vilnius, Lithuania, 2005. Vilnius:Technika, 809-812.

[9] Mira, P.; Enge, P. 2010. Global Positioning System: Signals, Measurements and Performance. Ganga-Jamuna Press. 569 p. ISBN 978-0-97095442-8

[10] Siler, B.; Spotts, J. 1998. Using Visual Basic 6. Special Edition. QUE. 830 p. ISBN 0-7897-1542-2

[11] Carnes, J. 2007. UTM Using your GPS with the Universal Transverse Mercator Coordinate System. MapTools. 45 p. ISBN $978-0971090118$

[12] Munir, M. 2011. AutoCAD 2012 3D Modeling. Dulles, Virginia. 345 p. ISBN 978-1-936420-21-6

[13] Randy, H. 2011. AutoCAD 2012 Tutorial - Second Level: 3D Modeling. SDC publication. 332 p. ISBN 978-1-58503-640-0 